MILITARY TECHNICAL COLLEGE CAIRO-EGYPT

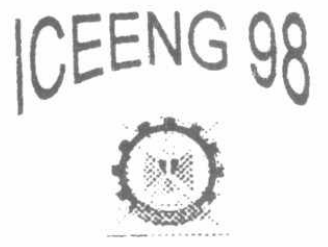

FIRST INTERNATIONAL CONF. ON ELECTRICAL ENGINEERING

\title{
STUDY OF DESFERRIOXAMINE-COPPER COMPLEX FORMATION
}

\author{
M.M.El-Dessouky*,M.W.Abdel-Raouf**, A.A.Baraka ***
}

\begin{abstract}
Desferrioxamine-Copper complex was investigated. The effect of $\mathrm{pH}$ and the ratio of desferrioxamine to copper were studied. The apparent stability constants for complex formed at different $\mathrm{pH}$ values were determined. The effect of adding EDTA (desferrioxamine of $1 \%$ EDTA)on complex formation ratio and stability was studied.The results showed an increase in absorbance and stability in case of EDTA addition and the chelation ratio (metal chelate) also changed from $1: 1$ to $2: 1$.
\end{abstract}

\section{KEY WORDS}

Desferrioxamine, Copper, Chelation, Drug, Internal decontamination.

\section{INTRODUCTION}

Heavy metal contamination of environment is common at many hazardous waste sites in many industrial zones. Lead, chromium, cadmium, copper, zinc, and mercury are most often observed metal contaminants. In numerous national sites, they have been found to be at elevated concentrations

Activities contributing to heavy metal contamination of environment include vehicle emission, mining, smelting, metal plating/finishing, battery production, recycling, agricultural/industrial chemical applications, and incineration processes.

Heatvy metals are toxic to people and pose a great risk for safe groundwater su'pply[1-3].Unbalancing bodies with such metal causes a number of diseases and removal of such toxic elements from bodies is of great importance[4].

This study investigates The formation of Desffereoxamine-copper complex by the continuous variation method Copper decontamination using desferrioxamine and enhanced desferrioxamine as a drug is encouraging [5-6].

* Egyptian Arnicd Forces.

** Dr. Hot Laboratory , Atomic Energy Authority, Cairo, Egypt.

*** Egyptian Armed Forces. 


\section{MATERIALS AND METHODS}

The salts used: $\mathrm{Cu}$ (II)chloride, desferrioxamine, sodium hydroxide, hydrochloric acid were of analytical grade Bidistilled water was used for preparation of stock solutions.

The samples of desferrioxamine-copper complex were prepared with different values of $f$, where $f=[C u] /[C u]+[D][3] .[D]$ is the concentration of desferrioxamine and $[C u]$ is the concentration of copper such that $[C u]+[D]=$ constant value .The value of $f$ varies from 0.1 to 0.9 . The samples were prepared from different volumes of solutions of desferrioxamine and copper of concentration $5 \times 10^{-2} \mathrm{M}$ such that the total volume of a sample was $5 \mathrm{ml}$. The $\mathrm{pH}$ of prepared samples and the reference samples were adjusted at 5,7 and 9 by the pH meter FISHER model 230A.

The optical measurements of the samples were carried out at laboratory temperature, of $25^{\circ} \mathrm{C}$, by a shimadzu UV-Visible spectrophotometer UV-160. The samples of desferrioxamine and desferrioxamine-copper complex were evaporated gently under IR lamp till dryness then the IR spectra of the crystals obtained were recorded using ATI unicam FTIR.

\section{RESULTS}

Figure(1) demonstrates the spectra of $\mathrm{Cu}(\mathrm{II})$, desferrioxamine , and desferrioxaminecopper complex (symbolized $\mathrm{Cu}-\mathrm{D}$ ) at $\mathrm{pH} \mathrm{5,7}$ and 9. The peaks of $\mathrm{Cu}(\mathrm{II})$ and $\mathrm{Cu}-\mathrm{D}$ are at $805 \mathrm{~nm}, 640 \mathrm{~nm}$ respectively with no peaks for desferrioxamine in the range of spectrum under study.

Figure(2) demonstrates the spectra of Cu-D complex for different values of $f$ at $\mathrm{pH}$ 5,7 and 9.Results show that $\mathrm{Cu}-\mathrm{D}$ was formed at $f=0.5$ for different $\mathrm{pH}$ values 5,7 and 9 with the maximum wave length $\lambda$ at $640 \mathrm{~nm}$. The absorbance values $A$ at maximum wave length were plotted against the corresponding values of $f$ in figure (3).

From the curves the apparent stability constants $K^{\prime}$ of the complex formed with ratio $\mathrm{M}: \mathrm{D}$ equals $1: 1$ (at $\mathrm{f}=0.5$ )at $\mathrm{pH} 5,7$ and 9 were calculated using job's method as follows $[7,8]$ :

$$
K^{\prime}=\frac{[\mathrm{CuD}]}{[\mathrm{Cu}][\mathrm{D}]}=\frac{\mathrm{Cu}+\mathrm{D} \rightleftharpoons \mathrm{CuD}}{\left(\frac{\mathrm{A}^{\prime}-\mathrm{A}}{\mathrm{A}^{\prime}}\right) * \mathrm{C}^{*} *\left(\frac{\mathrm{A}^{\prime}-\mathrm{A}}{\mathrm{A}^{\prime}}\right) * \mathrm{C}}=\frac{\frac{\mathrm{A}}{\mathrm{A}^{\prime}}}{\mathrm{C}^{*}\left(1-\frac{\mathrm{A}}{\mathrm{A}^{\prime}}\right)^{2}}
$$

where $\boldsymbol{A}$ is the actual absorbance of the complex, $\boldsymbol{A}^{\prime}$ is the limiting absorbance if all ions were transferred completely to the complex form and $C$ is the concentration of desferrioxamine at $f=0.5$. By substitution of values of $\boldsymbol{A}, \boldsymbol{A}^{\prime}$ and $C$, the apparent stability constant values $\boldsymbol{K}^{\top}$ were calculated and found to be $1676,4201.4$, and 6964.7 for complex. formed at $\mathrm{pH} 5,7$, and 9 respectively.

Figure (4) demonstrates the UV spectra of (1\%EDTA desferrioxamine)-copper complex (symbolized $\mathrm{Cu}-\mathrm{DE}$ ) for different values of $f$ with the maximum wave length $\lambda$ at $640 \mathrm{rum}$ at $\mathrm{pH} \mathrm{5,7}$ and 9 . 
Proceeding of the 1" ICEENG conference, 24-26 March, 1998.

ECH.1 556

(a)

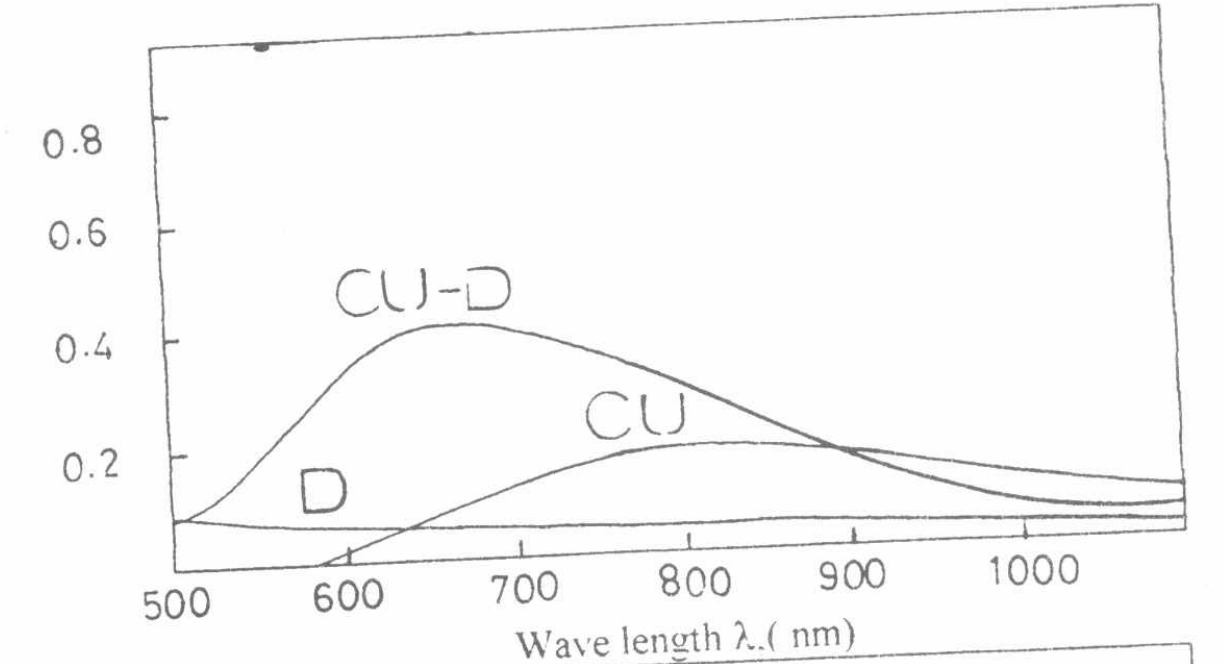

(b)
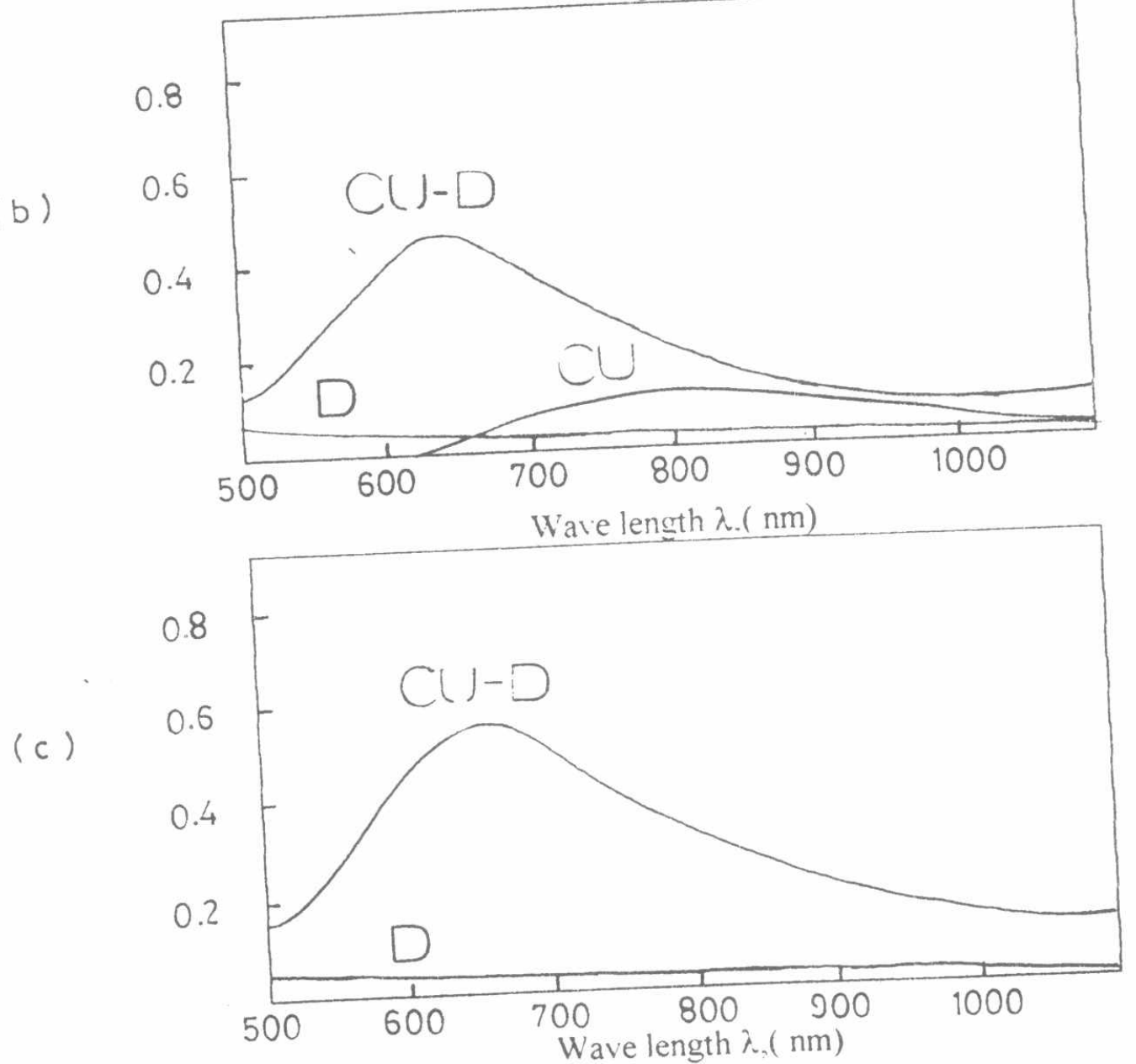

Fig.1. Spectra of $\mathrm{Cu}(\mathrm{II})$, Desf .Cu-D complex at $\mathrm{pH} 5(\mathrm{a}) .7(\mathrm{~b})$, and $9(\mathrm{c})$. 
Proceeding of the I" ICEENG conference. 24-26 March, 1998
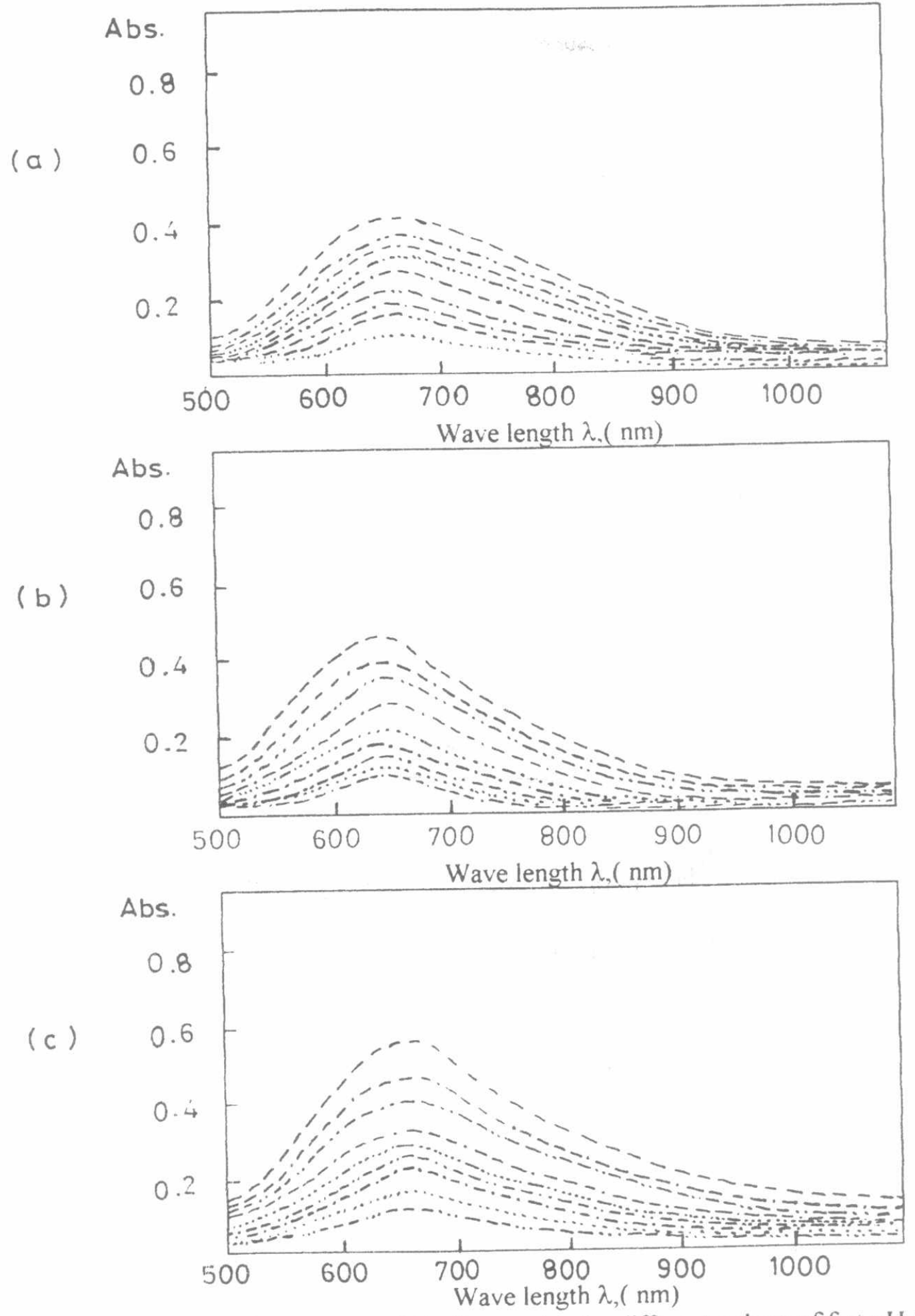

Fig.2.Absorption spectra of Cu-D complex for different values of $\mathrm{f}$ at $\mathrm{pH} 5$ ( a ), $\mathrm{pH} 7$ (b), and pH 9 ( c ) denoting for $\mathrm{f}=0.1, \ldots / \mathrm{f}=0.2, \ldots / \mathrm{f}=0.3, \ldots . / \mathrm{f}=0.4, \ldots . . / \mathrm{f}=0.5,-\cdots$ $/ \mathrm{f}=0.6,-. . / \mathrm{f}=0.7-\ldots . . . / \mathrm{f}=0.8,-. . / \mathrm{f}=0.9,-\cdots \ldots$ 
Proceeding of the 1*t ICEENG conterence, 24-26 March, 1998

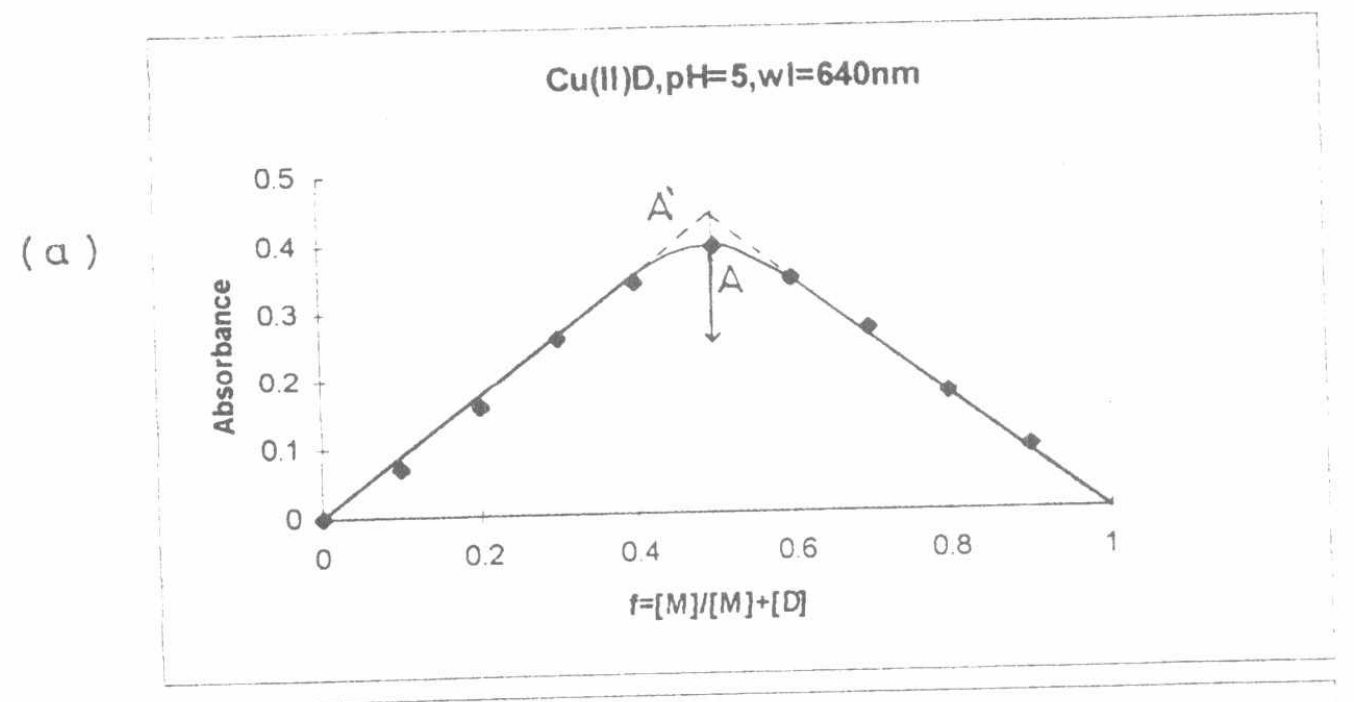

(b)

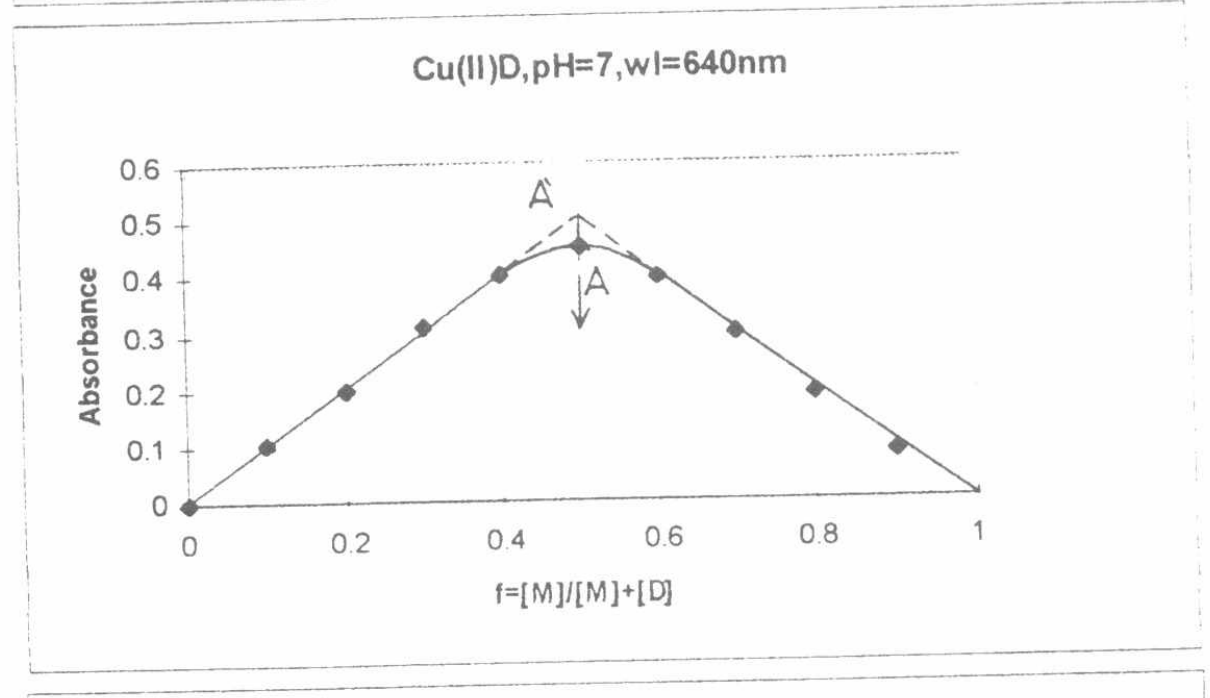

$$
\mathrm{Cu}(I I) \mathrm{D}, \mathrm{pH}=9, \mathrm{wl}=640 \mathrm{~nm}
$$

(c)

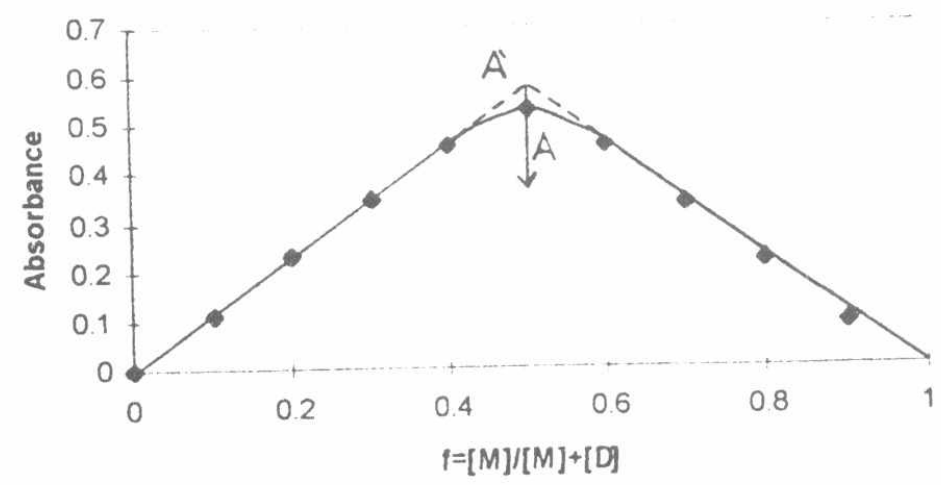

Fig.3. Variation of optical absorbance $A$ with $f$ at $\lambda=640 \mathrm{~nm}$ for Cu-D at $\mathrm{pH}$ $5(\mathrm{a}), 7(\mathrm{~b})$, and $9(\mathrm{c})$ 
Figure (5) displays the absorbance values $\boldsymbol{A}$ at maximum wave length drawn against corresponding values of $f$. The results showed that complex $\mathrm{Cu}-\mathrm{DE}$ was formed at $f=0.66(\mathrm{M}: \mathrm{D}=2: 1)$.

$K^{\prime}$ for $\mathrm{Cu}-\mathrm{DE}$ can be determined as follows :

In case of complex formation $\mathrm{M}: \mathrm{D}$ as $1: 2$ we have ;

$$
\begin{gathered}
2 \mathrm{Cu}+\mathrm{D} \rightleftharpoons \mathrm{Cu}_{2} \mathrm{D} \\
\therefore \mathrm{K}^{\prime}=\frac{\left[\mathrm{Cu}_{2} \mathrm{D}\right]}{[\mathrm{Cu}]^{2}[\mathrm{D}]}
\end{gathered}
$$

Let $C$ is the concentration of desferrioxamine at equilibrium;

$$
K^{\prime}=\frac{\frac{A}{A^{\prime}} * C}{\left(\frac{\Delta A}{A^{\prime}} * 2 C\right)^{2}\left(\frac{\Delta A}{A^{\prime}} * C\right)}=\frac{\frac{A}{A^{\prime}}}{\left(\frac{\Delta A}{A^{\prime}}\right)^{3} * 4 C^{2}}
$$

Where $\Delta \mathbf{A}$ equals $\mathbf{A}^{\prime}-\mathbf{A}$.

The apparent stability constants $\boldsymbol{K}^{\vee}$ were calculated and found to be $1.188 \times 10^{5}$ ,3.527 $\times 10^{4}$, and $1.133 \times 10^{5}$ for the complex formed at $\mathrm{pH} 5,7$, and 9 respectively. Therefore it can be concluded clearly from results that addition of small amount of EDTA (1\%) cause high reactivity of desferrioxamine for complexation since it changed the ratio of $M: D$ from $1: 1$ to $2: 1$ and produced more stable complexes with higher $\boldsymbol{K}^{\top}$ than without addition of EDTA

Figure (6) shows the IR spectra of desferrioxamine at pH 5,7,and 9. The comparison shows that the structure of desferrioxamine changes as $\mathrm{pH}$ value changes, and this is due to the presence of amino groups which are sensitive to $\mathrm{pH}$ value.

Figure (7) demonstrates the IR spectra of $\mathrm{Cu}-\mathrm{D}$ complex at the same $\mathrm{pH}$ values 5,7 , and 9 . From figures $(6,7)$ it is clear that the structure of not chelated desferrioxamine differs from that in the complex form at each value of mentioned $\mathrm{pH}$ with slight difference at $\mathrm{pH}$ 9.This structure difference is only due to formation of complex. 
Proceeding of the I" ICEENG conference, 24-26 March, 1998

ECH.1 560

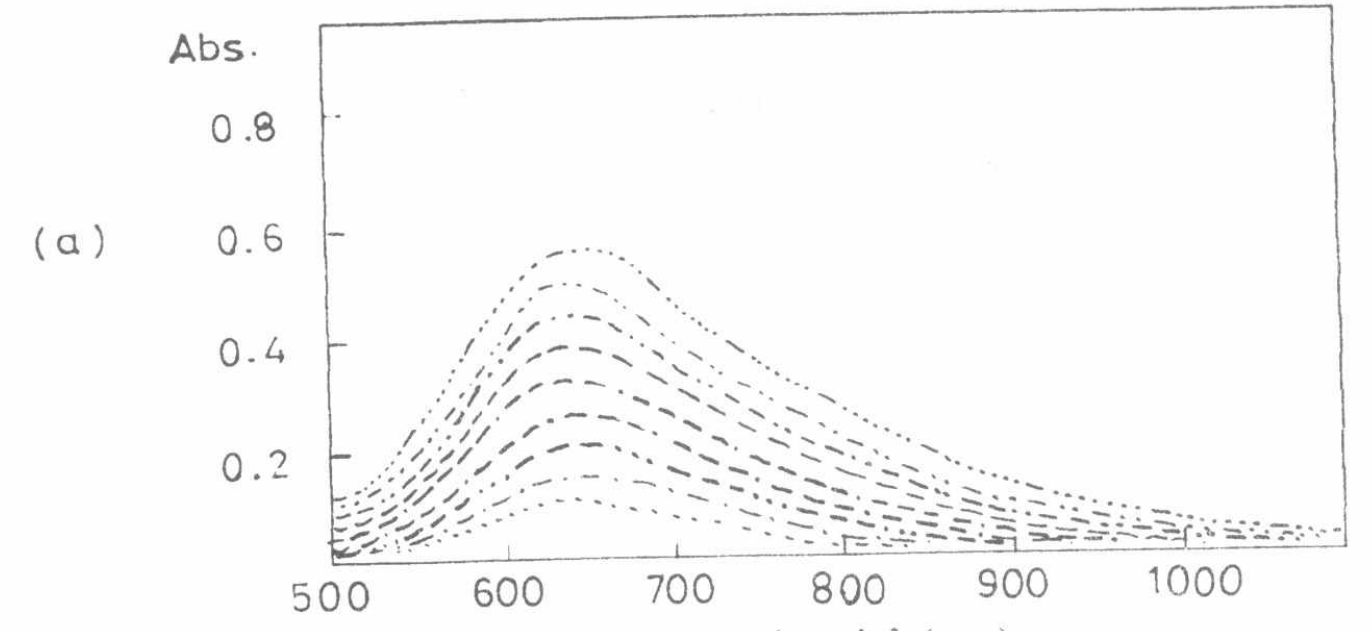

Wave length $\lambda .(\mathrm{nm})$

(b)
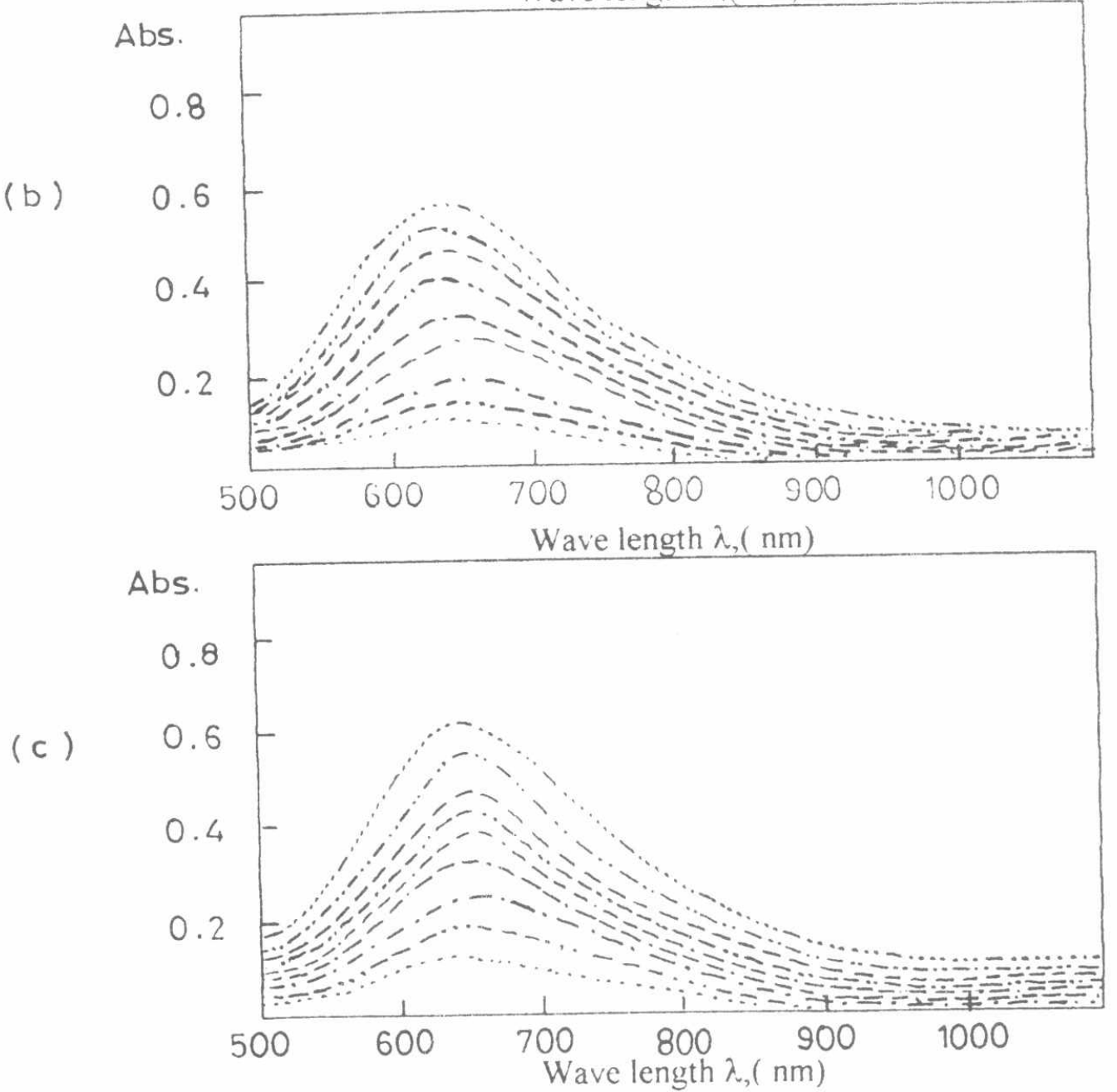

Fig.4. Absorption spectra of Cu-DE complex for different values of $\mathrm{f}$ at $\mathrm{pH} 5$ ( a ), pH 7 (b), and $\mathrm{pH} 9$ ( c ) denoting for $\mathrm{f}=0.1, \ldots / \mathrm{f}=0.2, \ldots / \mathrm{f}=0.3,--. / \mathrm{f}=0.4, \ldots . . / \mathrm{f}=0.5, \ldots$ $/ \mathrm{f}=0.6, \ldots / \mathrm{f}=0.7-\ldots . . . / \mathrm{f}=0.8,-\ldots / \mathrm{f}=0.9,-\cdots$ 
Proceeding of the 1" ICEENG conference, 24-26 March, 1998
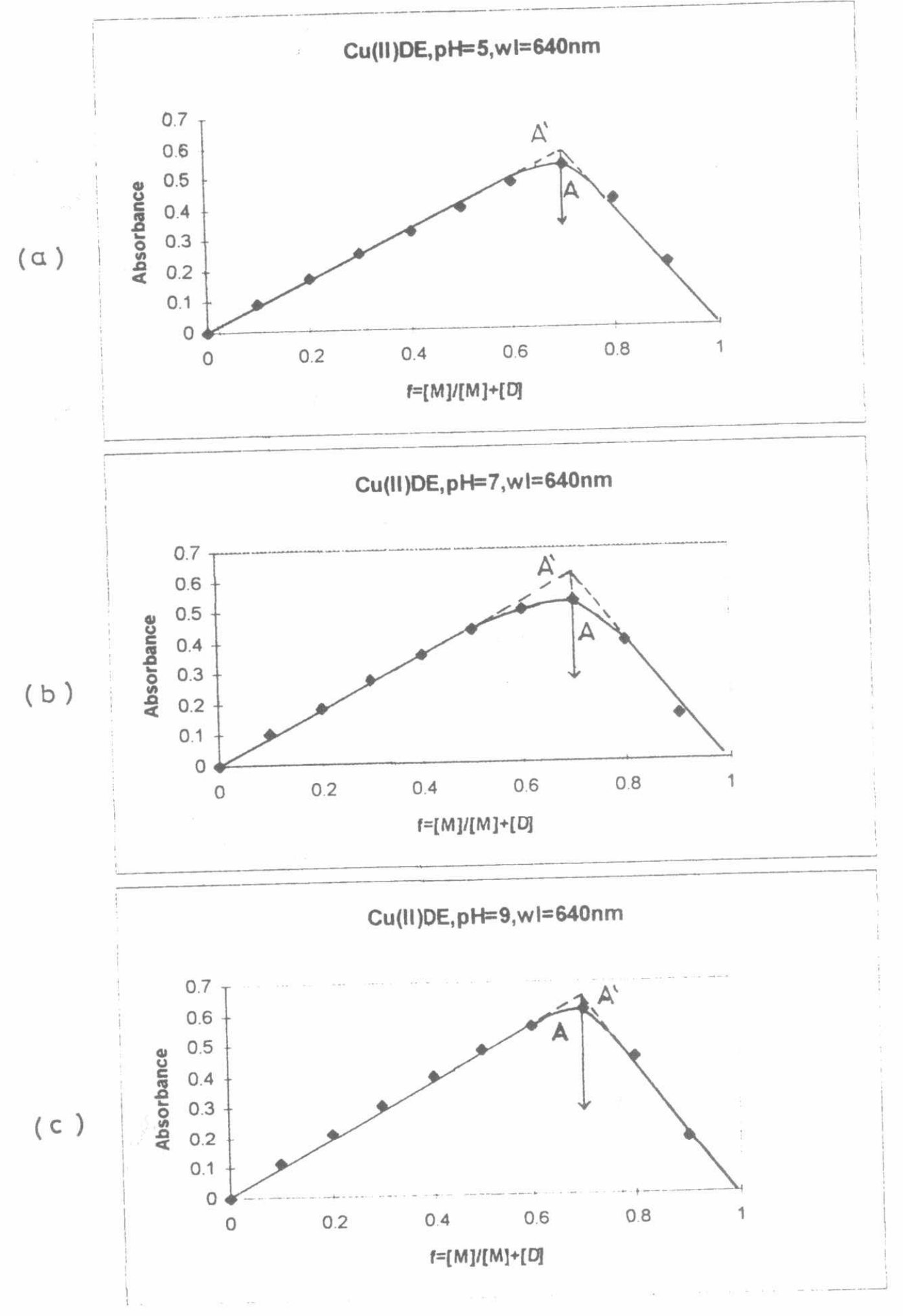

Fig. 5. Variation of optical absorbance $A$ with $f$ at $\lambda=640 \mathrm{~nm}$ for Cu-DE at pH $5(\mathrm{a}), 7(\mathrm{~b})$, and $9(\mathrm{c})$ 
Proceeding of the $1^{\text {st }}$ ICEENG conterence. 2t-26 March, 1998

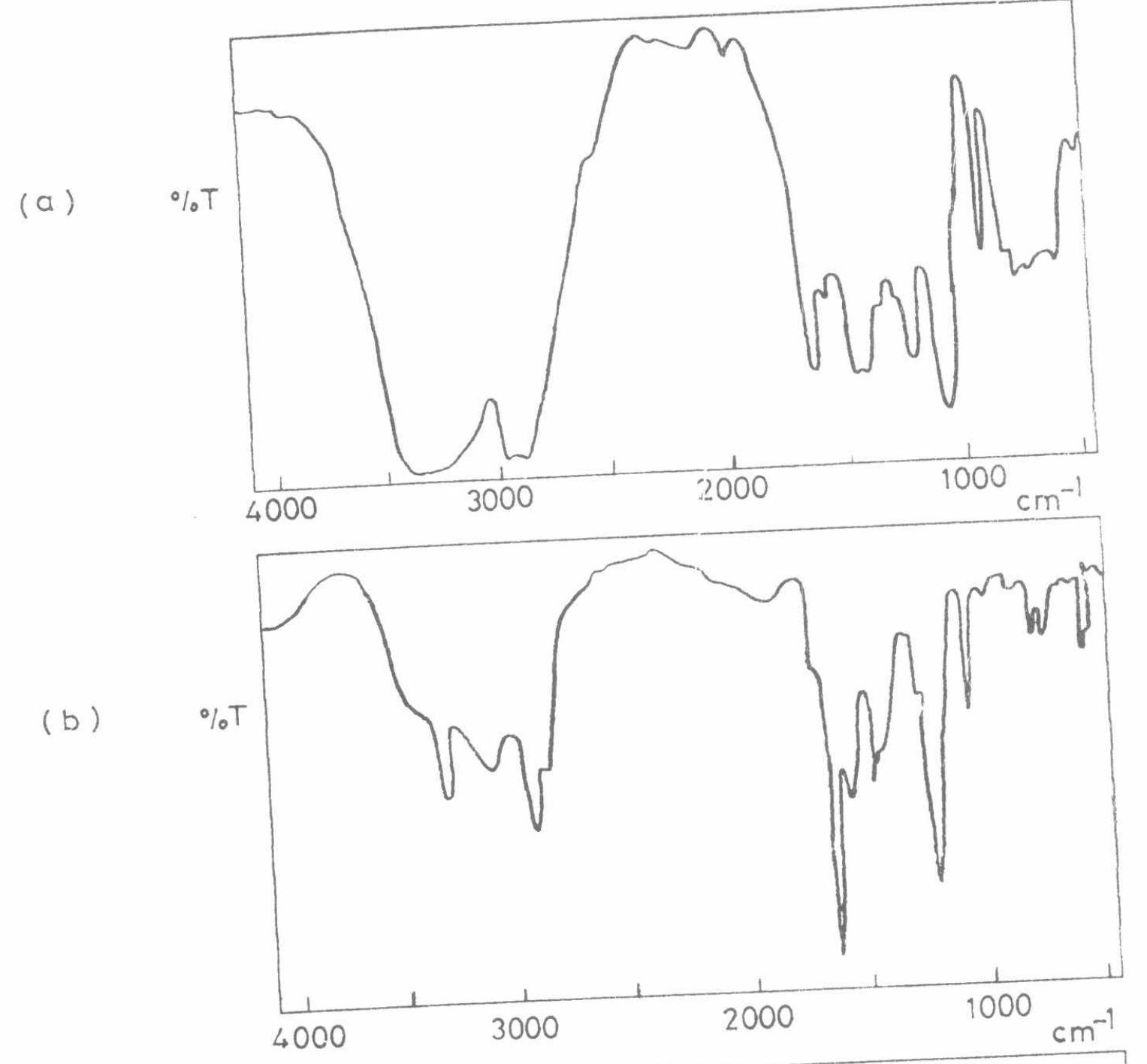

(c)

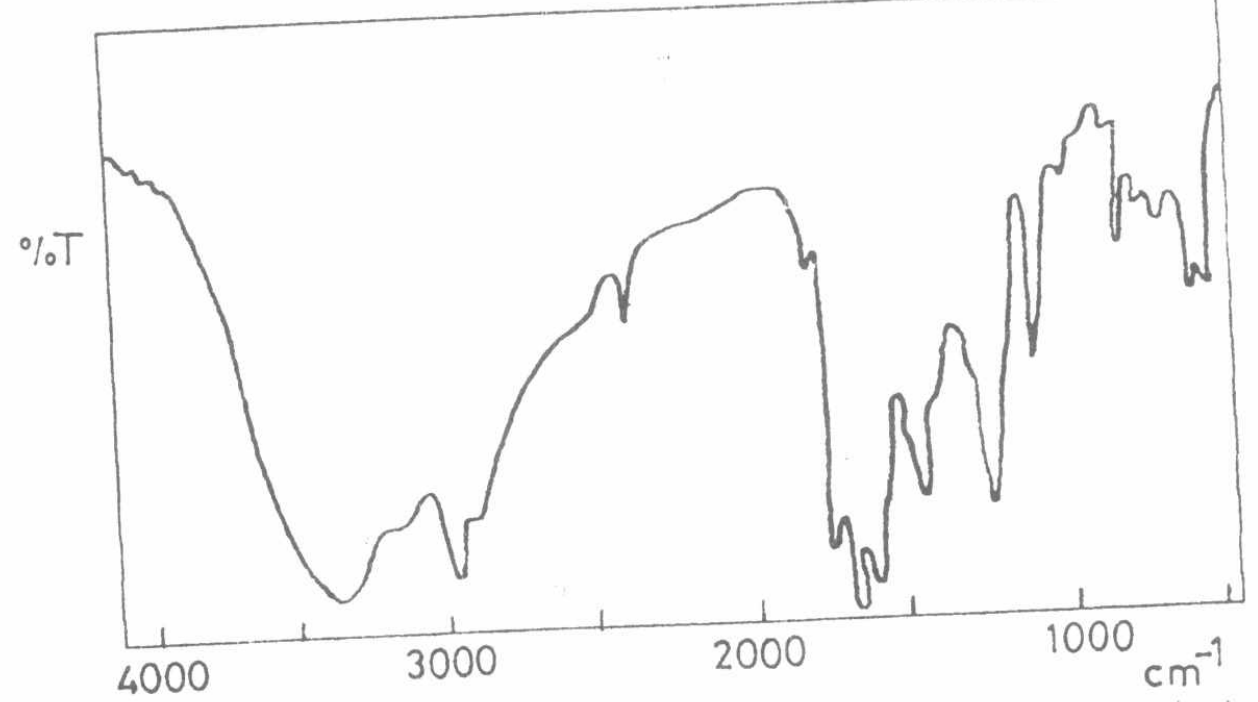

Fig. 6. IR spectra of desferrioxamine at $\mathrm{pH}_{5}$ ( a ), $\mathrm{pH} 7$ ( b ), and $\mathrm{pH} 9$ ( c ). 
Proceeding of the $1^{\text {st }}$ ICEENG conference. 24-26 March, 1998
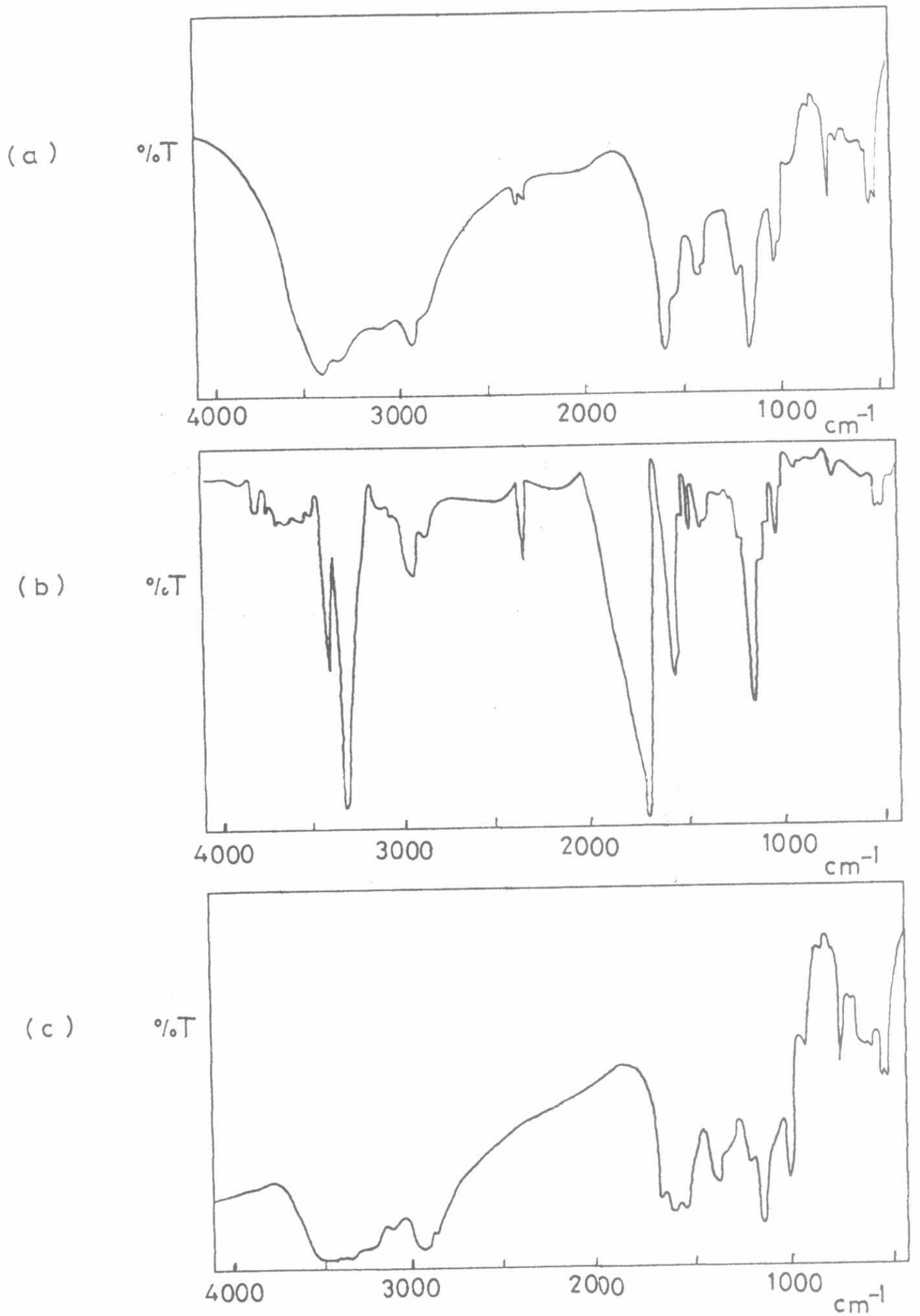

Fig. 7. IR spectra of Cu-D complex at $\mathrm{pH} 5$ ( a ), $\mathrm{pH} 7$ ( b ), and $\mathrm{pH} 9$ (c). 


\section{CONCLUSION}

Desferrioxamine shows good affinity towards copper and stable Cu-D complexes for studied range of $\mathrm{pH}$ are formed. The addition of EDTA by only $1 \%$ to desferrioxamine decreased the amount of desferrioxamine needed to chelate the same amount of copper to one half and thus the side effects of its administration are minimized.

This result is very important for practical use of desferrioxamine as an effective chelating drug for internal decontamination of human body in case of excess copper toxicity or excess radioactive copper

\section{REFERENCES}

1- Ringbom A,"Complexation in analytical chemistry". Willey. Intersclence, New York,(1963)

2- Shaker,M,Thesis of Ph.D. "Radioactive Decontamination of Equipment from Some Radioactive Isotopes by Formation of Chelates ,Military Technical College,Chem.Eng.Dep.,(1989)

3- Ting-Chien Chen,Andrew Hong,"Chelation extraction of lead and copper from an authentic contaminated soil using $\mathrm{N}$-(2-acetamido)iminodiacetic acid and Scarboxy-methyl-1-cysteine", Journal of Hazardous materials 41(1995)147-160.

4- Cowan S.T.and Rowatt E."The strategy of chemotherapy", Cambridge University press London,(1958).

5- Martin Dale, Extra pharmacpia $30^{\text {th }}$ edition. The universally acclaimed source of drug information. The pharmaceutical press.

6 William B.Deichmann \& Horace W.Gerarde" Toxicology of Drug and Chemicals"'(1969)

7- Lippincott,Merk, Verhoek" Determination of the formula of a complex ion by spectrophotometric method by job's method of continuous variation", Experimental General Chemistry $2^{\text {nd }}$ edition.

8- Sillen L.G.and Matrell,A.E." Stability constants of metal ion complexes ",special publication No.17, Chem. Society, London, 1954, Supplement Vol.1,Special Publication No.25, 1971 . 